REVIEW

\title{
National mental health policy - 1996, what has been achieved: a review
}

\author{
Upadhaya KD*
}

\author{
Consultant Psychiatrist Kathmandu Model Hospital \& Advisor, Community Mental health and \\ Counseling $(C M C-N)$ Nepal.
}

E-mail *Corresponding author: kapil.upadhyaya@yahoo.in

\begin{abstract}
Neuropsychiatry conditions account for a significant proportion of the global burden of disease. Significant numbers of people of developing economies of the world often tend to be deprived of quality mental health services and even if they receive them and they tend not be evidence based. In such condition policies on mental health act as guides to render quality mental health services at affordable price to the needy population.

The paper presents a review the mental health policy of Nepal-1996 on the basis of the basic objectives outlined by the policy and also tries to analyze whether those objectives have been attained as of date. The focus on four major aspect of the policy document i.e. access and availability to basic mental health services, development of required manpower, protection of fundamental human rights of mentally ill, improve awareness about mental health, mental disorders, and the promotion of mentally healthy life styles.
\end{abstract}

Keywords: Mental health policy, mental health, review mental health policy

- - - - - - - - - - - - - - - - - - - - - - - - - - - - - - - - - - - - - - - -

\section{INTRODUCTION}

$\mathrm{H}$ ealth systems around the world face enormous challenges in delivering care and protecting the human rights of people with mental, neurological and substance use disorder. The resources available are insufficient, inequitably distributed and inefficiently used. As a result, a large majority of people with these disorders receive no care at all ${ }^{1}$. Neuropsychiatry conditions together account for $10.96 \%$ of the global burden of disease as measured by Disability Adjusted Life Years (DALYs) ${ }^{2}$. About four out five people in low- and middle-income countries who need service for mental, neurological and substance use conditions do not receive them. Even if they receive some treatments, they are not evidence based and of the required standards. Improper diagnosis and symptomatic treatment is often the case when patients seek treatment at the primary health care level.

In 1975 - already 36 years ago World Health Organization (WHO) stated "detection and management of priority mental disorders should form part of the regular tasks of primary health workers"3. National Mental Health Policy $1996^{4}$ which is regarded as an excellent policy with strategies and plan of actions has four main objectives:

1. To ensure the availability and accessibility of minimum mental health services for all the population of Nepal by the year 2000: in particular for the most vulnerable and under privileged groups of the population, by integrating mental health services into the general health service system of the country, and by adopting other appropriate 
measures suitable to the community and the people.

2. To prepare Human Resources in the area of Mental Health in order to provide for the above mentioned Mental Health Services - this will include mental health training of all health workers, preparation of specialist Mental Health manpower, and training of the groups as per need.

3. To protect the fundamental human rights of the mentally ill in Nepal.

4. To improve awareness about mental health, mental disorders, and the promotion of mentally healthy life styles, in the community by participation of the community structures, amongst health workers.

Objective 1- Minimum Mental Health Services for All: This policy is not fully implemented yet and so minimal mental health service has not been available to most vulnerable and under privileged

Just for a reference about the importance of mental health, The Central Council of Health, the country's highest health policy making body of India in 1982 adopted a resolution for implementation in the states and Union Territories of the country as follows:

"Mental health must form an integral part of total health programme and as such should be included in all national policies and programmes in the field of Health, Education and Social Welfare. Realizing the groups of the population. However, a few NGOs are working in the field of mental health and they are either providing community mental health service to selected districts of Nepal or rehabilitation service to some severely mentally sick patients. Several NGOs are also working with substance use disorder especially alcohol and drug use disorder. Most of the rehabilitation centers however charge fees and they are not accessible to poor and under privileged population with some exceptions of free treatment to selected cases.

During the past 15 years or so many medical college hospitals, and hospitals in private sector have started functioning and most of them are providing psychiatric services. Except in the far- western region and remote hilly districts, health facilities have significantly increased in other parts of Nepal. Medical college teaching hospitals charge some fees and private sector hospitals are expensive so poor and under privileged do not afford to get health service from these institutions.

Ministry of Health and Population has created posts for the psychiatrist in Regional, Zonal and other referral hospitals, a very good move to provide the mental health service from these hospitals. At present hospitals like Biratnagar, Birgunj, Bharatpur, Pokhara, Butwal and Nepalganj are providing mental health service. These hospitals also serve as the referral points to provide specialist service including mental health.

About two years ago, Ministry of Health and Population decided to provide free medicines for certain medical conditions from district hospitals, primary health centers, health posts and sub-health posts. Unfortunately, common mental health conditions were not included for free medicines. importance of the mental health in the course curricula for various levels of health professionals, suitable action should be taken in consultation with appropriate authorities to strengthen the mental health Education components. While appreciating the efforts of the Central Governments in pursuing legislative action on Mental Health Bill, the joint conference expressed its earnestness to see that the bill takes a legal shape at the earliest" 5

Similarly, on September 4, 2007, The Lancet launched a new movement for mental health, through the publication of six key articles. The key messages from the series of articles are:

"First, mental health is a neglected aspect of human well- being, which is intimately connected with many other conditions of global health importance. Second, resources for mental health are inadequate, insufficient, and inequitably distributed. Third, there is already a strong evidence base on which to scale up mental health services. Fourth, most lowincome and middle -income countries currently devote far too few resources to mental health. Fifth, there are critical lessons to learn from past 
successes and failures - for political leadership and priority setting, for increasing financial support, decentralizing mental health services, for integrating mental health into primary care, for increasing health worker trained in mental health, and for strengthening public health perspectives in mental health. Finally, any call to action demands a clear set of indicators to measure progress at country level ${ }^{6,7^{\prime \prime}}$.

If the planners and decision makers give importance only to these two key messages given above, mental health in Nepal will get its due importance in the future. Alternatively, Ministry of Health can form a panel of experts in mental health who can recommend policy, plans and programmes keeping in mind the available resources.

Objective 2- Human resources: Some progress has been made in this regards. Before 1990, there were just 10-12 psychiatrists in the country, two or three psychiatric nurses and hardly any clinical psychologists working in mental health. In 2010, number of psychiatrists were 54 or more with one child psychiatrist, clinical psychologists -10 , and mental health nurses -28 8. Number of psychiatrist and psychologist will go on increasing every year, which is again very good for the mental health service. But we do not have qualified psychiatric social workers and occupational therapists in the country at present. As mental health service is a team work and role of psychiatric social worker and occupational therapist is equally important.

Though the number of human resources has increased, without proper utilization of these resources, delivery of the services will not be efficient. In the absence of good opportunity, brain drain is likely as already some psychiatrists have left for countries like Australia and United States of America. Many qualified psychiatrists have joined different medical colleges of the country, which is again good as psychiatric department will provide the mental health service in various locations of the country.

Mental health service is a team work and mostly this team consists of psychiatrist, clinical psychologist, psychiatric nurse and psychiatric social worker. Occupational therapist is also necessary for hospital setup. But in the health ministry's organogram, there is no post for clinical psychologist, and also no separate post for psychiatric nurses even in the only one mental hospital. If one post of clinical psychologist and one post of psychiatric nurse can be created in the referral hospital along with the post of psychiatrist, mental health team will be formed and the team will work for the improvement of mental health service.

As regards the mental health training of doctors and health workers, with the financial support of $\mathrm{WHO}$, several batches of doctors and health workers have been trained in the past. In the recent years, Management Division and National Health Training Center (NHTC) are taking interest in the mental health training of district doctors and paramedical and nursing staffs since 3 years or so. This is again a very positive attitude from the Government. CMCNepal an NGO primarily working in the area of mental health for the past many years is working in collaboration with the Government in such training. CMC-Nepal has also developed training manual and special package training schedule in mental health short course of 5 days mainly focusing on most common mental disorders and epilepsy like depression, psychosis, epilepsy and alcohol use problems and long training of 10 days covering some of the other mental disorders like anxiety disorders, somatization disorder, mental retardation, childhood mental disorders, suicide and role of counseling in mental health. Psychiatrist from TU Teaching hospital, medical college hospitals and mental hospital are invited as facilitators during such training.

Supervision, monitoring the work of the trained staffs, evaluation of their work and data collection are however not satisfactory in the absence of which, it is difficult state how effectives are these training and whether the patients are benefitting or not from such activities. Ministry of Health and Population / Department of Health Service has not recognized the mental health service as a priority programme, or its National Programme, so even the trained staffs give more attention to priority programme keeping aside mental health work as an added burden. District health offices 
express desire to have specified letter from the Government/ Department of Health Services directing them to give priority in mental health. In the absence of such letter, district offices naturally have to give more time and effort to priority health conditions. So unless the Government takes over mental health service as a National Health Programme and gives equal status as for the general health service, such trainings can not contribute to significantly improving mental health service.

Objective 3- Protecting the human rights of mentally ill: The first of these human right principles is that there shall be no discrimination on the ground of mental illness. Another principle is every patient shall have the right to be treated and cared for in his or her own community. And a third is that every patient shall have the right to be treated in the least restrictive environment ${ }^{9}$.

United Nations General Assembly Resolution $46 / 119$ on the protection of persons with Mental Illness and Improvement of Mental Health Care, adopted in $1991^{10}$. There are 25 principles which fall into two general categories: civil rights and procedures, and access to and quality care. Principles include statement of the fundamental freedoms and basic rights of mentally ill persons, criteria for the determination of mental illness, protection of confidentiality, standards of care and treatment including involuntary admission and consent to treatment, rights of mentally ill persons in mental health facilities, provision of resources for mental health facilities, provision of review mechanisms, providing for protection of the rights of mentally ill offenders, and procedural safeguards to protect the rights of mentally ill persons.

When we talk about Nepal, we do not have mental health legislation as yet though its draft was first submitted in the year BS 2056(2000 AD) and second revised draft in BS 2060 (2007 AD) . Unfortunately, no further action was taken by the ministry of health. Again the second Draft was reviewed in BS 2068 (2011 AD) and a five member committee has been formed to update this draft and to submit to Ministry of Health and Population.
Objective 4- Awareness about mental health, mental disorder and promotion of mentally healthy life styles: With World Health Organization's financial support, radio and television programmes were run in the past for 5 years or so with the aim of raising awareness, and reducing stigma. A panel of experts usually the psychiatrists talked about various aspects of common mental disorders in Nepal Television and sometimes also in the television of private sector. For the radio programme, one psychiatrist used to talk about one common psychiatric disorder in an interview covering common presentations, causes, diagnosis, treatment and duration of treatment in simple language for the general population.

As no impact study was done, we do not know how effective these programmes were. We used to see at least a few cases immediately after these television and radio programmes in the hospital or in the clinics. Patient or the patient party used to give reference of TV show or the radio programme to us. In the past, there used to be only one radio station, Radio Nepal and only one national TV channel, Nepal television. As there are so many FM stations all competing for hot news and playing popular songs in between, people are more attracted towards these FMs. There are so many television channels again competing to attract the people, it is uncertain how effective is Nepal television at the community level. Awareness raising and the service has to be there side by side for its effectiveness. Such awareness programmes in the radio and television are very expensive and so they were discontinued.

National Health Education, Information, Education and Communication Center in the Department of Health Service can contribute significantly to raise awareness and reduce stigma, if they incorporate education and information about common mental disorders, alcohol use problems and suicide problems in their annual plans.

\section{REFERENCES}

1. Dr Margaret Chan Director - General World Health organization Mental Health Gap Action Programme 
2. Mathers, Lopez, and Murray. The Burden of Disease and Mortality by Conditions: Data, Methods, and results for 2001". Global Burden of Disease and Risk factors. 2006.

3. Declaration of Alma-Ata.in International Conference on Primary Health Care. 1978. Alma-Ata, USSR: World Health Organization.

4. National Mental Health Policy -1996.

5. Murthy RS. Mental Health Care in India 1947-2007.Indian Journal of Psychiatry. 76-82

6. Chisholm D, Flisher AJ, Lund, Patel $P$, Saxena S, Thornicroft G, Tomlinson M, Lancet Global Mental Health group (2007a) Scale up services for mental disorders; a call for action. Lancet; 370:1241-1252.

7. Chisholm D, Lund, C, Saxena S. Cost of scaling up mental health care in low and middle income countries. British Journal of Psychiatry; 191: 528-535.

8. Mental Health Manual for Health Workers: Commitment for the Promotion of Mental Health \& Psychosocial Support in Nepal.

9. Message from the Director -General Gro Harlem Brundtland; WHO Geneva October 2001: World Health Report 2001

10. Mental Health: New Understanding, New Hope. The World Health Report 2001. The World Health Organization

11. Draft Mental Health Legislation Govt. of Nepal / World Health Organization Kathmandu, Nepal 2007. 